\title{
Representaciones de pobres y pobreza en los agentes de la Política Social argentina
}

Conceptual representations of poor people and poverty in Argentina's social policy officers

\author{
María Belén Aenlle \\ Licenciada en Trabajo Social y Magister \\ en Política Social, Universidad de Buenos \\ Aires. Docente de Investigación Social, \\ Universidad Nacional de Moreno. \\ baenlle@yahoo.com.ar
}

\section{Resumen}

A pesar de su relevancia, las representaciones conceptuales de quienes intervienen en el diseño y la implementación de políticas sociales son un campo poco trabajado. Sostenemos en este artículo que las representaciones constituyen un factor importante para comprender cómo se reproducen, se modifican y coexisten paradigmas dominantes y alternativos respecto de las problemáticas, los grupos y los individuos involucrados, y revelan cómo se producen o perpetúan significaciones y acciones en relación a las personas pobres y a la pobreza. El objetivo general de este trabajo es describir y analizar las representaciones de pobres y pobreza en el imaginario de planificadores e implementadores de políticas sociales; para ello se propone una construcción tipológica con base en tres categorías de representaciones: institucional transformadora, institucional tradicional y esencialista.

Palabras clave: representaciones, pobres, pobreza, desigualdades, agentes de la política social.

\footnotetext{
Abstract

Notwithstanding the relevance of the conceptual representations of policy officers involved in both the design and implementation of social policies with regard to poverty, little academic attention has been addressed to them. In this work we assess their relevance in order to understand how prevailing and alternative conceptual or ideological paradigms of poor people and poverty at large, contribute to produce and eventually to perpetuate policy interventions
} 
and meanings with regard to the persons and situations to which policies are addressed. Our main goal is to build a typology of these representation as well to discuss the ways they influence social policy-making and implementation. Three categories of representations are thus identified: institutional transformative, institutional traditionalist, and essentialist.

Key words: representations, poverty, poor people, inequalities, social policy effectors.

\section{Introducción}

El modelo sociopolítico que se impuso en la Argentina en la década de 1990 significó una profunda transformación social: crecimiento de la desigualdad, de la desintegración social y aumento de la pobreza. La necesidad de las ciencias sociales de dar cuenta de las nuevas formas de pobreza condujo a la delineación y al perfeccionamiento de distintos instrumentos de medición, más que abrir una instancia de discusión que posibilitara repensarlas política y conceptualmente, tendencia en la que influyeron los requerimientos de los organismos internacionales involucrados en las estrategias y políticas respectivas. Aunque paralelamente se observa un incremento de los estudios e investigaciones cualitativas, éstos están centrados en la descripción y comprensión de las estrategias de vida de las personas pobres y, en menor medida, en sus subjetividades y autopercepción de la pobreza, así como en los modos como se describen las diferentes categorías de pobreza. Si bien existen algunos estudios de las representaciones presentes en los programas sociales, no ha tenido la misma relevancia el abordaje de las representaciones sobre pobres y pobreza de los diversos agentes de la política social, de planificadores y de implementadores; nos interesa entonces recorrer este camino poco transitado. La importancia de esas representaciones radica en que ellas gravitan en el diseño de los programas, en las acciones y en la conformación del "sentido común" que se despliega alrededor de la pobreza y la desigualdad. Ellas devienen un factor relevante para comprender cómo se reproducen, se modifican y coexisten paradigmas dominantes y alternativos, y cómo se producen o perpetúan significaciones en relación a las personas pobres y a la pobreza.

En años recientes se ha producido en Argentina cierto alejamiento de la política social neoliberal; prueba de ello son la Asignación Universal por Hijo (AUH) y los cambios en la política laboral y previsional, entre otros. Pero el modelo asistencial de política social construido por el neoliberalismo aún mantiene presencia.

En este artículo nos proponemos hacer un primer acercamiento a varios interrogantes sobre el tema, con relación al modo como los planificadores e implementadores de políticas sociales posteriores a 2003 se representan a las personas pobres y a la pobreza. En primer lugar planteamos algunas consideraciones sobre nuestra comprensión del con- 
cepto de representaciones y de su relación con las políticas sociales; a continuación discutimos su importancia e implicaciones en los actores de la política social. Sobre la base del análisis de entrevistas en profundidad efectuadas a planificadores e implementadores, proponemos una tipología de sus representaciones, formulando por último algunas interrogantes referidas principalmente a las lógicas en pugna que están presentes en ellas y a la relevancia de su comprensión para un mayor conocimiento de las problemáticas presentes en la elaboración y ejecución de las políticas sociales.

\section{Representaciones y designación de identidades}

Para poder acercarnos a la relación de la Política Social y las representaciones, resulta necesario presentar algunas perspectivas y debates en torno a dicha noción de representaciones, de manera de puntualizar algunos aspectos y nociones que tendremos en cuenta en nuestro análisis.

Desde distintas disciplinas y sus múltiples enfoques, el concepto de representaciones, presenta variadas acepciones y perspectivas, haciéndose central en todas, la relación entre los elementos objetivos y subjetivos de los procesos sociales y el vínculo entre lo individual y lo social, entre las formas de conocer objetivas e intersubjetivas.

Moscovici (1986: 472) observa que "en tanto que fenómenos, las representaciones sociales se presentan bajo formas variadas, más o menos complejas. Imágenes que condensan un conjunto de significados; sistemas de referencia que nos permiten interpretar lo que nos sucede, e incluso dar un sentido a lo inesperado; categorías que sirven para clasificar circunstancias, fenómenos e individuos con quienes tenemos algo que ver; teorías que permiten establecer hechos sobre ellos". También resalta que las representaciones son un "conjunto de conceptos, declaraciones y explicaciones originadas en la vida cotidiana, en el curso de las comunicaciones interindividuales que equivalen, en nuestra sociedad, a los mitos y sistemas de creencias de las sociedades tradicionales; pudiendo, incluso, afirmarse que son la versión contemporánea del sentido común" (Moscovici, 1981: 181). Las representaciones no están limitadas a ser un reflejo del mundo, sino que pueden ser algo diferente, en las representaciones los seres humanos completan el mundo o le agregan elementos (Raiter, 2002: 13). Por su parte Altamirano (1990: 12) afirma: “...al destacar el carácter imaginario de determinada representación, o constelación de representaciones, símbolos, significaciones, lo que se subraya es no sólo la línea que la separa de lo considerado real, sino también su carácter no reflejo...lo imaginario es, pues, inventivo, productivo, no meramente reproductivo...”.

De acuerdo a estas argumentaciones y siguiendo a Vasilachis (2003: 102) entendemos las representaciones sociales como formulaciones sintéticas de sentido, descriptibles y diferenciables, producidas por actores sociales como formas de interpretación y simbo- 
lización de aspectos clave de su experiencia social; como construcciones simbólicas que los sujetos crean o a las que apelan para interpretar el mundo, reflexionar sobre su propia situación y la de los demás, así como para determinar el alcance y la posibilidad de su acción histórica, fijando identidades, posiciones sociales y formas de acción.

Una de las funciones de las representaciones, fundamental para el tema que estamos trabajando, es la designación de identidades. Baczko (1991:28) sostiene que las representaciones designan identidades colectivas, fijando modelos formadores como el de "jefe", "buen súbito", "valiente guerrero", "militante", etc., modelos que no funcionan como simples tipologías descriptivas, sino que marcan "territorios" y fronteras, definiendo relaciones con los "otros", formando imágenes de "amigos" y "enemigos", de rivales y aliados. Esta institución de identidad (Bourdieu, 1985: 81), es fundamental porque impone un nombre, asigna una esencia social, impone un derecho de ser y hacer, marca límites y fronteras. Es importante destacar que, como muestra Raiter (2002), los contenidos de las representaciones no son neutros, se toman decisiones, se planifica la vida, se elijen objetivos, a partir de, teniendo en cuenta o condicionados por las imágenes que se tienen de los acontecimientos y hechos del mundo. Nunca se actúa desde los hechos u objetos en sí, sino desde las representaciones construidas.

En la construcción de imágenes el sujeto es necesariamente activo, y estas imágenes constituyen las creencias del sujeto sobre el mundo. El sujeto tiene creencias acerca de "los otros", de las "identidades" y de las "diferencias"; el papel de las creencias previas es fundamental en la construcción de nuevas representaciones (Raiter, 2002). Las representaciones y las creencias se relacionan así con la institución de identidades, con la esencia social, que Bourdieu (1985) define como el conjunto de atributos y atribuciones sociales que produce el acto de institución, y con el concepto de identidad existencial queVasilachis (2003) considera como uno de los dos elementos constitutivos de la identidad. Esta autora plantea que la identidad está conformada por el elemento existencial y por el elemento esencial o identidad esencial. En el primero los sujetos que poseen bienes económica o socialmente valiosos, marcan la diferencia en la posesión y en la privación de otros, asignando acciones, atribuciones y calificaciones, que legitiman y justifican posiciones, consolidando relaciones de poder y dominación, negando el segundo elemento, lo común que es propio y que puede ser desarrollado por todos. A lo que sumamos que estas acciones, atribuciones y calificaciones, se constituyen en creencias sobre la identidad de la persona, y se generalizan conformándose como estereotipos.

Ahora bien, cuando hablamos de la igualdad en la identidad esencial no estamos retomando posiciones del individualismo sino reafirmando justamente que las desigualdades son relacionales, que son creaciones sociales. Así, si bien todos los sujetos son esencialmente iguales, los poseedores de bienes económica o socialmente valiosos tienen más posibilidades de nombrar e imponer sus representaciones, provocando el adve- 
nimiento de esa realidad, por la eficacia propia de la evocación, de lo que representan (Bourdieu, 1985). En palabras de Foucault (1993) el poder produce lo real, produce campos de objetos y rituales de verdad, por lo que se hace aún más interesante analizar las representaciones de los actores o grupos con poder de nombrar. La desigualdad persistente entre categorías surge porque las personas que controlan el acceso a recursos productores de valor resuelven problemas organizacionales por medio de distinciones categoriales. Una categoría aglutina actores considerados semejantes y define relaciones entre ambos; las categorías se centran en límites (Tilly, 2000: 75). El trabajo categorial siempre implica atribuir cualidades distintivas a los actores, a uno y otro lado de los límites (Tilly, 2000: 79).Y en los límites que separan de los miembros de otras categorías, los sujetos recurren a la interacción, el miedo, la esperanza y la imaginación para construir historias que mantengan esos límites. Así las creencias compartidas desempeñan un papel significativo en el funcionamiento de la desigualdad categorial y limitan las alternativas organizacionales, que los participantes consideran, temen o desean (Tilly, 2000:114). Las representaciones y las creencias de los sujetos con poder de nombrar, intervienen entonces más fuertemente en la creación de categorías y clasificaciones, de estereotipos, en la delimitación de fronteras y posibilidades, manteniendo y justificando las desigualdades sociales.

\section{Política Social, actores y representaciones}

Los diferentes modelos de política social tienen relación con diversas representaciones sobre la pobreza; varios autores les conceden particular importancia. Por ejemplo Álvarez Leguizamón (2001), al proponer una tipología de programas para gestionar la pobreza en la Argentina, toma en cuenta tres dimensiones: la forma de articulación (relación jerárquica y funciones asignadas a las distintas instituciones participantes); la manera en que se asignan y canalizan los fondos a los destinatarios; y la que considera más importante: la representación de la pobreza que tiene el programa. Ampliando esta visión Cardarelli y Rosenfeld (2000: 58) sostienen que todo programa o proyecto social opera sobre la base de una concepción social y política convalidada respecto de quiénes son "los otros"; no solamente en términos de cuáles son las categorías de personas en "condiciones de riesgo" que requieren intervención estatal, sino a partir de una representación social de la vida cotidiana de los “diferentes", de sus necesidades y expectativas. En esta línea Tenti Fanfani (1992) afirma que las políticas asistenciales contemporáneas, proclamándose participativas, promocionales y centradas en las necesidades, por lo general también presuponen una serie de necesidades, prioridades y preferencias de las poblaciones. De manera coincidente, afirma Danani (2006) que la política social y los programas sociales condensan, manifiestan, y vehiculizan representaciones sobre la "generalidad del orden" y "los modelos socialmente deseables", sobre quiénes son "los otros" e imponiendo de determinadas representaciones que son objeto de luchas simbólicas. 
Participan y deciden en este campo actores cuyas interacciones preparan y condicionan las decisiones centrales de una política (Aguilar Villanueva, 1996: 25) y actores que la implementan y desde esa implementación también construyen y reconstruyen las políticas sociales.Vale decir, estamos en presencia en consecuencia de un habitus particular, donde se diseñan e implementan las políticas como lugar de producción y reproducción social, y a los sujetos que participan del mismo no solo como reproductores de ideologías dominantes. Al respecto es interesante lo planteado por Escolar (2000: 32): "En la medida en que los individuos se identifican con los fines de la institución aceptándolos como válidos, en esa medida la institución existe y se reproduce. Sin embargo, en cuanto cada individuo imprime en su relación con la institución su historia personal y su vinculación con otras instituciones esta reproducción siempre será algo diferente, y por lo tanto, siempre será creación, producción de algo nuevo, en la medida en que su inserción en estas instituciones adopta formas organizacionales específicas y singulares, tampoco se trata de una mera proyección subjetiva y aislada". Los actores que intervienen en las políticas provienen de recorridos y trayectorias heterogéneos; operan con supuestos y categorías relativas a la comparación y comportamientos de la "realidad", que configuran "modelos conceptuales", "marcas de referencia", implícitos o explícitos, que determinan la manera de describir los hechos, de definirlos y problematizarlos, de clasificarlos y explicarlos, condicionando las acciones (AguilarVillanueva 1996:36).

Decimos entonces que el espacio institucional en que estos actores se reúnen está atravesado por el paradigma vigente y dominante y por una construcción política, técnica y social de la pobreza, construcción vinculada a una historia y a este período histórico particular, construcción que cristaliza y legitima las percepciones y modalidades de intervención del estado y la sociedad como paradigma de políticas sociales (Cardarelli y Rosenfeld, 2000). Pero si bien es importante el peso de este discurso dominante, son también importantes las representaciones de quienes tienen poder y autoridad de nombrar y clasificar a las personas pobres. Cada actor tendrá representaciones acerca de los "pobres" y "la pobreza” y en la conformación habrán intervenido: su posición en el espacio social, su socialización, su preparación técnica, etc.; e intervendrán también, de maneras diversas, tanto en la conformación como en la reelaboración, los postulados del paradigma vigente, las lógicas de los organismos internacionales, del propio estado nacional, y del espacio concreto en que se diseñan e implementan las políticas. Los actores sociales, incluso los agentes del estado, reproducen y producen, desde su posición en el espacio social, representaciones que interactúan con las que se vehiculizan en el aparato del estado, es importante comprender estas representaciones y esta interacción para comprender la Política Social y la reproducción de las desigualdades. 


\section{Las representaciones de los planificadores e implementadores de la Política Social.}

A los efectos de proceder con nuestro análisis, seleccionamos tres experiencias programáticas, posteriores a 2003, del ámbito nacional, provincial (Prov. de Buenos Aires) y local (ciudad de Chascomús). Los programas analizados y tomados como marcos referenciales e institucionales de planificadores e implementadores, fueron entonces: "Programa Familias por la Inclusión Social" (Ministerio de Desarrollo Social de la Nación); "El Trabajo Dignifica" (Ministerio de Desarrollo Social de la Provincia de Buenos Aires) y "Entre Todos" (Secretaría de Desarrollo Social de la ciudad de Chascomús). Al practicar esta selección consideramos que tales programas emergen de líneas o ejes asumidos como centrales y prioritarios por el gobierno nacional: familia, trabajo y alimentación.

Nuestro punto de partida plantea que la política social y, en particular, los programas sociales, se construyen y reconstruyen en las interacciones de múltiples actores. De acuerdo a esto, nos centramos en dos tipos de agentes: planificadores e implementadores. Es decir, nos referimos a personas que en forma diversa han participado en el diseño formal de un programa, y a personas que no han participado en el diseño formal, pero que implementan los programas territorialmente y con sus prácticas intervienen en el rediseño de los mismos.

En primer lugar llevamos a cabo un exhaustivo análisis de la documentación existente sobre los programas y de la información complementaria de los mismos (cartillas, orientaciones, etc.) Este abordaje nos permitió alcanzar un conocimiento minucioso de fundamentaciones, objetivos y metodología de los programas, como también apreciar, a través de la folletería complementaria, supuestos, planteos y expectativas. En segundo lugar realizamos veintidós entrevistas en profundidad (Taylor y Bogdan, 1986 y Ruiz Olabuenaga, 1996), quince de ellas a planificadores y siete a implementadores. Seis de las entrevistas a planificadores lo fueron a planificadores a nivel nacional, siete a nivel provincial y dos a nivel municipal. La mayoría de las personas entrevistadas que intervienen en el diseño de programas son mujeres; también es importante el número de las que tienen título universitario; las restantes cuentan con títulos terciarios. Prevalecen los trabajadores sociales; otras profesiones son Psicología, Psicología Social, Licenciatura en Ciencias de la Educación, Sociología, Economía y Abogacía. Dos entrevistas a implementadores se efectuaron en el municipio de Quilmes, otras dos en el de Trenque Lauquen y tres en el de Chascomús. Todas las entrevistadas son mujeres (esto no fue intencional sino que podría indicar que al menos a nivel local los agentes que intervienen en la implementación de programas sociales mostrarían una preponderancia de mujeres), de menor edad promedio que la de los planificadores; seis de ellas son trabajadoras sociales (universitarias y terciarias). Otra característica a tener en cuenta y problematizar, 
observada y surgida de las entrevistas, es que de las quince personas relacionadas con la planificación de programas solo menos de la mitad reconoce haber tenido o tener participación en política partidaria o participación religiosa, algunas de ellas en forma conjunta y otras solo participación política, y en los implementadores solo una de las entrevistadas manifiesta haber tenido participación política religiosa. También resaltamos que un número considerable de los agentes se han formado en la universidad y/o en instituciones públicas y que al menos la mitad ha continuado posteriormente su formación. Analizadas las entrevistas podemos señalar dos aspectos: la diversidad de perspectivas a observar, y la existencia de similitudes y diferencias dentro del universo entrevistado. Estas apreciaciones nos permitieron avanzar en la construcción de una tipología que, consideramos, contribuirá a incrementar el conocimiento de sus representaciones. Los ejes centrales de esta tipología son la caracterización y/o comprensión sobre las personas pobres y la pobreza, sobre las causas y las posibles formas de "superación", y sobre las acciones o intervenciones realizadas, pensadas o deseadas por estos agentes. En base a esos ejes presentamos tres tipos de representaciones: institucionales transformadoras, institucionales tradicionales, y esencialistas, distinguiendo y analizando matices dentro de cada tipo.

\section{Representaciones institucionales transformadoras: el valor de la experiencia y la interacción}

Varios elementos son centrales y comunes en las representaciones que llamamos "institucionales transformadoras": el valor de la experiencia, la apelación a la igualdad, la comprensión estructural de las causas de la pobreza, y la necesidad de políticas que combinen como actores al estado, a las organizaciones y a las personas en situación de pobreza. Los agentes con estas representaciones dan fundamental importancia y valor a la "experiencia", resaltan lo vivencial, el contacto directo con las personas con las que trabajan a través de los programas. Las vivencias son elaboradas, recortadas, reinterpretadas y visualizadas como elementos que modifican la vida personal e influyen en la trayectoria laboral. Si bien varios de ellos trabajan en el diseño de programas, esto no los mantiene alejados del "trabajo en terreno"; tienen también intervenciones directas con las personas en situación de pobreza. Para algunos de los agentes institucional transformadores el trabajo con las personas relacionadas al programa es una experiencia totalmente impregnada de los propios sentimientos y afectividad, siendo relevante el contacto personal y el "poner el cuerpo". El cuerpo aparece comprometido en las prácticas, afectado, conmocionado por los otros, por él pasan emociones, tensiones y dolores. Se habla también de "encontrarse" con el "otro" y del placer que implica este encuentro y el percibir que "sirve" lo que se hace, relacionándose con el sentirse vivo. Cobra paralelamente centralidad el "ponerse en el lugar del otro"y desde ahí interpretar y comprender sus acciones; una de las características de ese lugar "del otro" es el dolor, que parece no ser ajeno, sino vivido como propio. 
Uno de los elementos que definen a estas representaciones es la apelación al valor de la igualdad, los agentes consideran que "todos somos esencialmente iguales" aunque viviendo situaciones diferentes. Anteponen la palabra "persona" a la palabra "pobres", asignación que aunque parezca un dato menor, en este contexto convalida la visión de la igualdad esencial de las personas, al resaltar primeramente el elemento que define esa igualdad y posteriormente el que muestra la desigualdad. Remarcan así que el trabajo que realizan es con "personas en situación de pobreza" y no con "pobres", no hablando entonces de "beneficiarios". Afirman que todos tenemos necesidades y potencialidades; desde estos elementos comunes nace el encuentro y la mutua transformación. Señala Vasilachis (2003) en este sentido que frecuentemente y en diversos espacios la pobreza se define por la desigualdad y la carencia, pero sin que esa definición establezca un vínculo causal con éstas. Paralelamente, podemos pensar que se cuestiona el concepto de "cultura de la pobreza", al poner el acento en la persona, en la heterogeneidad y en que todos tenemos algo para dar, desde donde podríamos llegar a leer la producción en relación a una posición en el espacio social. Las personas no eligen ser pobres, sino que el sistema socio-económico produce y reproduce la pobreza. Se hace hincapié por lo tanto en el "estar pobre" y no en el "ser pobre", visión que también hace posible cierta descristalización de la pobreza ${ }^{2}$ y la visualización de los procesos que la generan. Se considera necesario el involucramiento porque las potencialidades que todos tenemos pueden "mutilarse" al vivir situaciones de pobreza. En este tipo de representaciones la persona en situación de pobreza no tiene que llegar a situaciones vividas y pensadas por los agentes (a una "inclusión” desde la visión hegemónica) sino que es desde el encuentro desde donde se piensan proyectos distintos, situaciones diferentes. Estos agentes consideran que la referencia frecuente de algunos programas a la necesidad de “construcción de capacidades" implica la suposición de que las personas en situación de pobreza no tienen estas capacidades. Contrariamente afirman que todos los sectores sociales necesitan trabajar en dicha construcción de capacidades. Subrayamos que en esta representación si bien no prevalece la imagen del pobre como indolente, está presente el supuesto de que el pobre tiene capacidades que se han visto debilitadas por "el círculo vicioso de la pobreza", pero paralelamente está presente el debate sobre qué capacidad determina la adquisición de la otra.

Es interesante observar que estos agentes acentúan lo afectivo, el cuerpo, la experiencia, el diálogo y la igualdad, hacen también referencia a su relación con el cristianismo y específicamente con la Iglesia Católica, al menos en sus primeros acercamientos a las situaciones de pobreza. Así en algunas de las entrevistas surge la explicitación de conceptos planteados por documentos del Magisterio de la Iglesia en Latinoamérica ${ }^{3}$, "todos somos esencialmente humanos", "promoción humana" y la insistencia en que esas potencialidades reconocidas también en las personas pobres pueden ser "mutiladas". Se enuncia cómo estos documentos sirvieron de puertas para intervenir y participar en esa "promoción humana". Sin embargo se muestra cierta crítica a lo que se considera 
específicamente religioso, como la catequesis o la evangelización. Cabría preguntarnos, cuando se habla de "mutilación" de potencialidades, si esta visión tiene algún punto de contacto con la de "falta de capacidades". La diferencia surge, sin embargo, del punto de partida de esta representación: la igualdad, así como de la intervendrían de otros procesos, personas y situaciones en la "mutilación" de las potencialidades.

Un rasgo diferenciador de las representaciones institucional-transformadoras es el reconocimiento y la valoración de los elementos subjetivos frente a los considerados como "técnicos", el valor que se asigna a lo político y a lo afectivo y su gravitación en las relaciones vinculares, de las prácticas y las acciones. Se afirma que poner énfasis en intervenciones "académicas" desligadas de lo político y lo afectivo es también una toma de posición, y que la objetividad, o la supuesta objetividad, es un elemento de control social. Se pone así en cuestión el concepto de "técnicos" de quienes participan en la política social, instaurado o fortalecido por el neoliberalismo. Se destaca el aprendizaje con la gente en el trabajo de campo, puesto al mismo nivel o por encima de la formación académica.A través del contacto directo se perciben e identifican transformaciones personales como también la transformación de las propias representaciones. Destacamos asî como elemento diferenciador respecto de los otros tipos de representaciones, el comprender el conocimiento como construcción conjunta con las personas en situación de pobreza, restando protagonismo a la posición de "profesional” y "agente de la política social", elemento que refuerza la visión de igualdad a la que apelan.

Desde estas representaciones la pobreza tiene causas estructurales y políticas y debe ser superada estructural y políticamente. El estado debe cumplir con su responsabilidad, pero es el protagonismo de las personas y de las organizaciones el que puede lograr transformaciones. Aunque los planificadores institucionales transformadores no ponen el acento en los "programas" en sí, sino en el contacto directo con la gente y en lo que ocurre en ese ámbito, reconocen una activa participación en el diseño de los mismos, en su reformulación constante, en relación a lo que va surgiendo y aconteciendo en las actividades desarrolladas "en terreno". Para estos agentes, por la importancia que otorgan a lo contextual, y también por el reconocimiento que hacen de las diversas características de las situaciones de pobreza, los programas deben ser diseñados teniendo en cuenta diferencias culturales, sociales y geográficas.

Dentro de este tipo, los implementadores muestran una diferencia con respecto a los planificadores. Si bien identifican la superación de la pobreza en lo político y ven necesaria una mayor presencia del estado, cuando se refieren a sus propias prácticas hacen alusión a la orientación, acompañamiento, seguimiento,, aconsejar tratamientos psicológicos, realización de actividades que permitan a las personas relacionarse y transferir habilidades. Estas prácticas parecen tener mucho en común con las que son mencionadas por agentes que participan de otros tipos de representaciones (especialmente las esen- 
cialistas), sin perjuicio de sus resignificaciones. Subrayamos que estos implementadores reconocen en sus espacios de trabajo la existencia de prejuicios con relación a la pobreza y a los "beneficiarios" de los programas, vinculados fundamentalmente a que las personas en situación de pobreza preferirían programas sociales a trabajar, que les pagan por llevar los chicos a la escuela. Paralelamente se hace mención a que es necesario trabajar esos prejuicios además de promover una legislación que genere mayor igualdad, asunto en el que el estado debe jugar un rol diferente y protagónico.

\section{Representaciones institucionales tradicionales: la importancia de la técnica y la capacitación}

Los agentes que se ubican en este tipo comprenden la pobreza como un fenómeno complejo en el que se marcan diferencias y se establecen clasificaciones que, se afirma, implican discusiones referidas a quiénes deben ir dirigidos los programas. Así algunas de las personas en situación de pobreza son "permeables", "salvables", "potables" o "reciclables" y otras "ya no lo son". Se trata de clasificaciones donde aparece claramente una representación que coloca en el "pobre" la responsabilidad de la pobreza, así como la capacidad o no de salir de ella; en este sentido, hay en tales clasificaciones una naturalización implícita de las relaciones sociales. Está presente en ellas la diferenciación de "nuevos pobres", "pobres estructurales", "indigentes" y "excluidos"; quienes pertenecen a estas últimas tienen menos posibilidades de cambiar de situación porque la clasificación también implica diferentes "beneficios" o acciones/intervenciones para las distintas categorías; esto no se explicita en los materiales impresos de los programas pero aparece explícitamente en el discurso de los agentes; se habla de "beneficiarios" y dentro de ese conjunto se establecen aquellas categorías. Los "nuevos pobres", se afirma, tienen más cerca la vivencia del trabajo, poseen otra formación, otra capacidad, han incorporado saberes que les dan otras oportunidades y pueden "reconvertirse" y acceder a programas productivos. Los "pobres estructurales" o de "familias históricamente pobres" no tienen esa vivencia, por lo que se considera tienen pocas actitudes y aptitudes hacia el trabajo. El tener o no la vivencia del trabajo tendría alguna relación con una cultura: la afirmación de que un sujeto "culturalmente tiene más cerca la vivencia del trabajo" estaría invocando implícitamente el concepto de "cultura de la pobreza". Se concluye así, de manera inmediata, que quien proviene de familias históricamente pobres, pocas veces trabajó y tiene pocas aptitudes y actitudes para hacerlo. Los primeros son "salvables"y/o "reciclables" y los segundos no; a éstos no corresponderían las políticas de promoción sino la asistencia.

En esta misma línea y reafirmando las discusiones que provocan las clasificaciones y las correspondientes líneas de acción, surgen más nominaciones para la clasificación, "los que están en el fondo del pozo" y los “que todavía no están en el fondo del pozo”. Para algunos de estos agentes es necesario tener políticas diferenciadas; para otros deben estar enfocadas solo en "los que están en el fondo del pozo", y para otros más "en los que 
todavía no cayeron", porque con menos recursos, y a través de la promoción, se pueden dar respuestas más rápidas. Por lo tanto se debe "sostener" a unos y ofrecerles políticas de promoción a otros. Las políticas universales se entienden como asociadas solo al empleo, mientras que los programas sociales no tendrían relación con lo universal. Se supone que quienes tienen empleo realizan elecciones libres (qué comer, cómo vestirse, cómo moverse), en tanto quienes no tienen empleo carecerían de tal posibilidad. Aquellos a quienes los técnicos consideran con más "capacidades" y "más posibilidades", son quienes pueden acceder a los programas. Entre tanto, los "indigentes" desarrollan estrategias de sobrevivencia, "laburan" buscando acceder a los recursos que les posibilita el estado u organizaciones sociales para la satisfacción de sus necesidades básicas, los más "astutos" logran así complementar ingresos de la mejor manera posible. Dado el tiempo y los esfuerzos que tienen que invertir en estas actividades se considera como dificil y contradictorio que puedan ser incluidos en emprendimientos productivos. Pero seguidamente a esta afirmación, se enuncia que muchos que ya no son "reciclables"; lo que primeramente sugería una visión positiva del esfuerzo de los "indigentes" para satisfacer sus necesidades se vuelve negativo, no solo por la apreciación de que no son "reciclables" sino también por la afirmación de que la población objetivo son "los vulnerables". Podemos suponer entonces que los "indigentes" quedan fuera tanto del empleo, de los programas socio-productivos, como de cualquier otra intervención.

Múltiples son las clasificaciones de la pobreza en estas representaciones. Expresar que alguien es "salvable" o "reciclable", implica una contraparte, alguien que está en condiciones de "salvar", que posee características, conocimientos, saberes que lo hacen estar o tener una posición desigual, que dan la posibilidad de "salvar" a otros. Posición desde la que también pueden nominar, demarcar quiénes son "unos" y "otros", atribuirles características diferenciadas y decidir sobre estos "otros", sobre qué les corresponde o no les corresponde.

Estos técnicos no hacen muchas referencias ni elaboran análisis sobre las causas de la pobreza, aunque sostienen que como consecuencia de las transformaciones neoliberales ella creció cuanti y culitativamente, y se perdió capital cultural y social, lo que dificulta la construcción de redes y de alianzas entre vecinos. Creen, simultáneamente, que no es necesario "diagnosticar” la pobreza, ya que ella siempre es igual y "urgente”. Muchas cosas cambian, pero la pobreza no; solo las personas que vivían en otro "lugar", en otra posición, y son "recién llegados" a este "lugar" de pobreza tendrían posibilidad de revertir la situación. En unos la pobreza es una situación, en otros, una característica. Unos no tienen capacidades, los otros sí y por eso la movilidad. Son sus capacidades y/o incapacidades las que pueden sumarlos, o dejarlos fuera del mercado.

El tiempo de permanencia en la pobreza es un factor que influye en las desigualdades en su interior: interviene en la pérdida de capital social y cultural, haciéndose necesario 
trabajar en la recuperación de ambos. Las capacidades y posibilidades de cada una de las clasificaciones se convierten en centrales; el apoyo a su desarrollo y la reconstrucción de los capitales sociales y culturales constituye el objeto de la intervención. Los “nuevos pobres" son nombrados como los perdedores o como los no beneficiados de un modelo económico; la pobreza de los "estructurales" tendría más que ver con características propias o adquiridas. Éstos últimos hacen algo por salir de su situación (conformando redes, juntándose con otros, capacitándose, etc.) y por medio de estas actividades se "sienten mejor". Insistimos en que no se hace mucha referencia a las causas de la pobreza y tampoco a su superación, pero el trabajar por "mejorar su calidad de vida" y porque se "sientan mejor", sería la vía de acción que se cree necesaria y posible.

Podemos preguntarnos si acaso desde estas representaciones se busca que por la capacitación y la participación los pobres logren una mejor calidad de vida, pero permaneciendo en los mismos lugares, no esperándose ni propiciándose cambios estructurales. Estos agentes hablan de acortar brechas, y la imagen de la brecha parece ser la de una hendidura que separa, una distancia sobre la que es necesario "construir puentes" y "generar dispositivos que las acorten". Estos puentes parecen ser para algunos -los que todavía pueden atravesarlos, los que tienen capacidades y no perdieron la "cultura del trabajo"-; a los "insalvables" los separarían brechas mayores y a ellos les corresponderían planes alimentarios. "Tender puentes" para quienes pueden transitarlos es tarea de los agentes; para ello deben identificar y superar obstáculos que parece tienen relación con "lo que falta", y lo que falta, desde la perspectiva de estos agentes, es capacitación, redes y sostén organizacional. Podemos observar que en estas representaciones el concepto de igualdad está ausente, si bien es difícil que alguien explícitamente apele a la desigualdad, no solo al efectuar esta clasificación de la pobreza, sino como venimos mostrando en esta contraposición "ellos" - "nosotros", y desde esta posición de poder "salvar" o "reciclar", podríamos suponer la presencia de esta apelación. Los agentes con representaciones institucionales tradicionales resaltan su condición de técnicos, el poseer títulos profesionales y habilitantes para trabajar en estas temáticas; la trayectoria dentro de la institución estatal también es factor de conocimiento importante para el diseño y la implementación de programas. Frecuentemente sostienen que es poca o nula su relación con los "beneficiarios" de los programas, su trabajo es con las organizaciones sociales; muestran también de esta manera su no involucramiento personal y una distancia que posibilitaría la aplicación de estos saberes técnicos.

Las organizaciones aparecen en estas representaciones como otro actor: son las intermediarias, las mediadoras de los programas, y sus integrantes tienen una situación diferente y "mejor" que los "beneficiarios"; no alcanzan el saber técnico de los planificadores, pero superan a quienes se encuentran en situación de pobreza. Las personas "beneficiarias" de los programas deben participar y asociarse, pero deben hacerlo en sus lugares y en base a las propuestas que se les hacen desde los programas. Esta participación no 
implica ser parte de la discusión de los mismos, ni entrar en relación con los "técnicos", dándose a entender que ello podría conducir a cuestionamientos a la posición del agente. El resultado de esto es el refuerzo de posiciones y distancias. Los planificadores institucional tradicionales se adjudican alta incidencia en el diseño e implementación de políticas, y la importancia que reconocen en el rol que juega el nivel político y/ o los organismos internacionales, ello disminuye su propia en el diseño. Por un lado se resalta el protagonismo en el diseño o en la hechura de programas y la libertad para el diseño, pero paralelamente se plantea la similitud de los programas de los diversos ministerios y se afirma que muchos programas mantienen líneas en el tiempo, solo modificando su nombre cuando cambian las autoridades políticas.

Consideramos que la inmovilización se convierte en una de las acciones características de los agentes institucionales tradicionales. Cuando hablamos de "inmovilizar" decimos que la pobreza y las personas pobres suelen tener en el imaginario de algunos decidores y planificadores un "lugar", una posición estable, no relacionada al cambio o las posibilidades de cambio, sino a la estabilidad y a la permanencia. Esta posición o lugar que se les asigna en la estructura social, muestra también la concepción de una sociedad jerárquica; se reconoce la heterogeneidad, pero como heterogeneidad jerárquica, donde hay distancias entre las posiciones y tanto las éstas como la inmovilidad, refuerzan en posiciones de poder a quienes tienen saberes y son funcionarios del estado. Así, inmovilizar a las personas pobres tendría relación con asignar algunas características personales, con esencializar una situación, vinculando estrechamente pobreza con falta de capacidades. Sostiene en este sentido Auyero (2001) que, en algunas concepciones y significaciones de este tipo, el pobre es quien está y continuará estando en su lugar, siempre en su mismo y eterno lugar, en lo bajo.

La capacitación suele funcionar como práctica contenedora. Se capacita para una mayor participación barrial o para el "fortalecimiento" familiar; ambas mejorarían la calidad de vida, la autoestima y la satisfacción personal. Contienen a las personas pobres, al hacer que "se sientan mejor"; se evitan conflictos pero también se evita el cambio o la superación de las situaciones de pobreza; se advierte también la persistencia de la idea del fortalecimiento de lazos. Álvarez Legizamón (1998) sostiene que lo que antes era considerado "rezago" o "traba" para el desarrollo, pasa a ser la solución para la superación de la pobreza. La solidaridad, los lazos de vecindad, etc. son fomentados desde los programas sociales, ya que ni el mercado ni las políticas de estado pueden contener el riesgo al conflicto social. En el "contener" al igual que en el "inmovilizar", se visualiza la pobreza como algo estático, desligándola de los procesos que la provocan. El discurso de estos agentes se centra en las que son consideradas esencias y no en lo relacional, estableciéndose una continuidad con el tipo que analizamos a continuación ${ }^{4}$. 


\section{Representaciones esencialistas: una cultura de la pobreza}

En este tipo de representaciones algunas de las características que se atribuyen a las personas en situación de pobreza son presentadas en relación a "estructuras psíquicas" particulares y otras a "características culturales". Se sostiene que son personas acostumbradas a pedir y a quienes se les otorga sin reclamarles ningún tipo de retribución, que el pedir y no recibir les provoca enojo. Una de las entrevistadas también afirmó que estas personas "demandan” y creen tener algún privilegio por conocerla a ella (porque ha trabajado como estimuladora temprana de sus hijos, o docente de los mismos en escuelas especiales, o por haber sido empleados de su familia). El trabajo asume centralidad en estas representaciones como pauta cultural básica, como base de la movilidad y la integración social y marca el límite entre grupos sociales. Las personas pobres "no tienen ganas de trabajar, ni de capacitarse", no tienen la "cultura del trabajo", esto parece provocar una suerte de autoexclusión, y convertirlos en portadores de pautas y comportamientos a ser sancionados, paralelamente son caracterizados por la imposibilidad de cambiar, mostrando y a su vez poniendo en juego, fuertes estereotipos que están vigentes socialmente o en el "sentido común", y que circulan a través de diferentes agentes y medios. Podríamos aquí encontrar un punto de contacto con las que llamamos representaciones institucional tradicionales, y con la clasificación que hacía referencia a personas "insalvables", fijadas en lugar y en una posición social inmodificable, siendo en estas representaciones mucho más importante y frecuente la esencialización de la pobreza, las referencias a una "cultura de la pobreza" a una "mentalidad" y a una "estructura psíquica".

La pobreza se transmite de generación en generación, es cultural, no cabría el cuestionamiento al estado ni al funcionamiento de la política social; habría una responsabilidad de los pobres por su propia pobreza. Se asocia la pobreza a sufrimiento, pero no serían los adultos pobres los que sufren sino los niños, lo que tendría que ver no solo con determinada concepción de la niñez sino también con la responsabilidad y/o culpa de los adultos pobres. La cadena de transmisión, podría cortarse educando a los niños, a los adultos "dan ganas de matarlos", expresión que nos recuerda a las oídas con frecuencia en la vida cotidiana "hay que matarlos a todos" o "a los negros hay que matarlos a todos". Se insiste en que las personas pobres creen que el estado tiene que garantizarles la cobertura de necesidades, que varias generaciones de familias pobres han recibido sin dar nada a cambio, sin "canjear", y esto es visto como negativo y como algo que interpela a los programas. Se propone que se exija algo a cambio de lo que se da, una contraparte (¿contraprestación?) que "reeduque" a los "beneficiarios”, que les "enseñe a pescar" . Se trata de miradas y apreciaciones que explicitan representaciones que a su vez se articulan con otras que, lejos de incorporar una perspectiva de derechos, lo hacen de una perspectiva individualista y cerrada. El pobre, por su cultura y por sus características es el responsable de su propia pobreza, por eso hay que promoverlo, capacitarlo, volverlo participativo, etc. 
Otra característica personal, psíquica y cultural, atribuida a los pobres está relacionada a la cantidad de hijos, el no uso de métodos anticonceptivos y la utilización de esto para obtener subsidios. Así la cantidad de hijos parece señalar un patrón cultural, un no saber y una estrategia utilizada para acceder al "beneficio" de los programas sociales o a la AUH, y así no solo al tener más hijos se reclaman más subsidios sino que, como está muy instalado en el sentido común, aquí también se afirma, que decidida y voluntariamente se tienen más hijos para recibir más subsidios. Estas personas viven en determinadas zonas y también pueden ser peligrosas; el acercamiento a un espacio geográfico territorial donde viven personas que reciben los "beneficios" de los programas es visto como amenazante. Un punto interesante que nos permite ver la relación de los pobres y el espacio territorial, y su vínculo con la segregación espacial y la desigualdad social.

Frente a las características y forma de vida que presentan las personas pobres el agente educa, acompaña, cambia pautas culturales, ejerce cierta tutela sobre los pobres. Las conductas de tutelaje, hacen referencia al menos a dos elementos contrapuestos, el pobre, que carece de, que no sabe, que no quiere, y a un "otro" diferente, el agente, que sí tiene, sabe, y que puede llevar a cabo esa tutela y orientación. La tutela puede reconocerse también en el discurso cuando una de las entrevistadas sostiene "tengo una señora...", y a esa señora la aconseja, le recomienda determinadas prácticas como el ligamiento de trompas. Se identifica una multiplicidad de causas de la pobreza, políticas, personales, educativas, de falta de trabajo, institucionales, si bien entonces aparecen causas macro, sin embargo el acento se pone en lo personal, se afirma que para hablar de causas hay que analizar el caso de cada familia en particular; por ejemplo, las causas educativas que a primera vista podíamos leer como macro o estructurales, se vuelven totalmente personales, ya que a estas personas "nunca les interesó leer ni escribir", "nunca les interesó el trabajo", no tienen motivación, la "pobreza viene desde la familia", y si la familia tiene estas características la generación siguiente las tendrá también. Desde estas representaciones se actualizaría la interpretación de Lewis (1961), en cuanto a que la "cultura de la pobreza" es una sub cultura, con una estructura y una fundamentación propia, un modo de vida trasmitido de una a otra generación, con determinadas características. Podríamos pensar también que los agentes esencialistas continúan poniendo más el acento en las dificultades para eliminar esta cultura que en la misma eliminación de la pobreza.

La vinculación que se plantea entre la pobreza y la falta de trabajo no se asienta en un análisis de procesos económicos y políticos; el factor preponderante parece ser la falta o pérdida de la "cultura del trabajo", la "falta de capacitación" y también la pérdida de valores y principios. El trabajo, ya dijimos, es un valor social, y desde estos agentes pareciera que algunas personas eligen permanecer al margen y es necesario disciplinarlas. No se cuestiona ni se analiza cómo repercute y qué implica para estas personas el no poder acceder a un empleo y el tener múltiples impedimentos y dificultades para lograr por medio del trabajo satisfacer sus necesidades y las de su grupo familiar. Así, podemos 
ver en estas representaciones el fuerte vínculo y encadenamiento entre pobreza y características personales y familiares. La "superación" de la pobreza está relacionada también a acciones personales y familiares, a la voluntad que pongan las personas para cambiar de situación. Surge en consecuencia una diferenciación: los "que tiran a progresar", "los que salen a flote", "los que quieren llegar a otro nivel" y los que "no les interesa nada”, los que "se quedaron ahí y ahí están", "los que quedan estancados", y a esta diferenciación corresponderían diferentes acciones por parte de los agentes. Las acciones e intervenciones que se realizan y que se consideran pertinentes, consisten en perseguir para(¿promover?) que se capaciten, controlar, hacer acompañamiento y seguimiento, estimular, apuntalar a quienes reciben los programas. Uno de los objetivos de esta estrategia es la recuperación de la "cultura del trabajo"; el acompañamiento es necesario porque la gente no sabe, o no puede sola. Insistimos entonces en que este concepto de "cultura de la pobreza" y numerosas comprensiones que parten del mismo o que están en relación con él mantienen una presencia importante, principalmente en los agentes esencialistas, pero identificándose algunos elementos también en los institucional tradicionales, en cuanto se trata de una visión fuertemente arraigada en el sentido común.

En resumen: podemos hablar de discursos, representaciones y prácticas como tres esferas que se distinguen, se articulan y se refuerzan. Si bien en el discurso político, y en algunos de los enunciados de los programas sociales implementados en años recientes se advierte cierto distanciamiento respecto de la visión hegemónica durante varias décadas, esa visión continuaría teniendo una fuerte presencia en las representaciones y especialmente en las prácticas de los agentes que actúan en contacto directo con los destinatarios de los programas.

\section{Lógicas diversas: desigualdad e igualdad}

En los tres tipos de representaciones podemos identificar puntos de convergencia y de divergencias, cuestiones y definiciones en pugna, propuestas de acción diferentes, distintas pertenencias y relaciones con los espacios institucionales. Podemos asimismo reconocer algunos tópicos, entendidos éstos como lugares comunes o de confluencia en la nominación de "los otros", de "los beneficiarios", de "los pobres". Si bien estos tópicos pueden ser resignificados y mostrar entonces algunas variaciones, constituyen soportes en la construcción, permanencia, consolidación y reproducción de lógicas diversas. Inicialmente podemos reconocer la presencia de la más fuerte de ellas, la lógica de la desigualdad, y otra, alternativa y menos instalada, la lógica de la igualdad.

\section{La lógica de la desigualdad y sus soportes}

Cuando hablamos de lógica de desigualdad hacemos referencia a mecanismos, modos, formas, que articulados operan en la producción y reproducción de la desigualdad, permitiéndonos este concepto abordar y comprender también la desigualdad como proceso 
relacional. La lógica de la desigualdad tiene relación directa con el concepto de "privación de identidad" de Vasilachis (2003: 255-256); con él esta autora muestra que cuando se niega, por diversas acciones o estrategias discursivas, la identidad esencial de las personas, se les está privando de identidad, creando diferencias, consolidando la desigualdad; y paralelamente legitimando el poder de unos sobre otros y creando distancias. Vasilachis hace referencia también a que quienes definen, explican e interpretan la pobreza pueden ser vistos como sujetos activos en posibles relaciones de privación. Podemos decir entonces que estas estrategias y/o soportes de la lógica de desigualdad son mecanismos que refuerzan las distancias sociales y niegan la igualdad esencial de los sujetos. Asimismo podemos evocar el concepto de Tilly (2000:21) de "desigualdad persistente"; para este autor existen mecanismos sociales, secuencias causales recurrentes de alcance general, que realmente fijan en su lugar la desigualdad categorial. Así las grandes y significativas desigualdades en las ventajas que gozan los seres humanos corresponden principalmente a diferencias categoriales, más que a diferencias individuales en atributos, inclinaciones o desempeños. La desigualdad persistente entre categorías surge porque las personas que controlan el acceso a los recursos productores de valor resuelven problemas organizacionales acuciantes por medio de distinciones categoriales; de manera inadvertida o intencional, establecen sistemas de cierre, exclusión y control social. En la lógica de la persistencia de la desigualdad, ésta no tiene que ver con una desigualdad esencial de las personas sino con lógicas colectivas que generan y hacen persistente esa desigualdad.

\subsection{Categorizar y clasificar: legitimización de la desigualdad social}

Ya hemos hecho referencia a la relación de las representaciones sociales con la elaboración de categorías y clasificaciones, y a su función en la legitimación de la desigualdad, como también a las características y la nueva relevancia que adquirieron en la política social neoliberal. Tanto en los agentes ligados a las representaciones institucionales tradicionales como a las esencialistas, y no así en los ligados a las institucionales transformadoras, observamos la presencia de esta función clasificatoria, y la utilización de las tipologías descriptivas para marcar relaciones con otros (Baczko, 1991: 3). Aparecen bajo palabras diferentes básicamente dos categorías de personas pobres: quienes parecen no tener posibilidades de cambiar su situación -"los estructurales", "los que no les interesa nada", "los que se quedaron ahí y ahí están", "los insalvables", "los no reciclables"-, y quienes sí tendrían estas posibilidades - "los nuevos pobres", "los que tiran a progresar", "los que salen a flote", "los salvables", "los reciclables"--

En su análisis de la política social neoliberal, Lautier (1998:163) observa que para realizar la selección de aquellos que son dignos de ser ayudados se mezclan inevitablemente datos con apariencia objetiva (conocimiento, etc.) y otros más subjetivos ("espíritu empresarial", "voluntad de salir a flote”); su señalamiento nos ayuda a identificar la presencia de aspectos subjetivos en los agentes del estado, en el diseño e implementación de programas. Cuando decimos subjetivos estamos también considerando con Bourdieu 
(1996) las condiciones objetivas que sirven de soportes y desencadenantes de esta dimensión subjetiva. Así, al analizar a "los que ganaron" en el modelo neoliberal, Svampa (2001) muestra cómo, en las representaciones de esos ganadores, el pobre es antes que nada una clasificación y hace hincapié en la prevalencia de algunos "tópicos clásicos" acerca de la pobreza: entre ellos la visión meritocrática y la tarea pedagógica y hasta civilizatoria que deben ejercer las clases superiores con relación a los pobres -concepción que, hemos visto, se encuentra presente con fuerza en la meritocrática de los agentes de la política social y en la naturaleza pretendidamente pedagógica de sus intervenciones. Siguiendo a Martínez (2007: 215) advertimos en esta función clasificatoria, la dimensión simbólica vinculada inmediatamente a posiciones en el espacio, posiciones que implican diferencias de poder y desigualdad estructural. Este es el punto de partida en que se inscribe cualquier interacción simbólica, incluso convertida ella misma en relación de fuerza simbólica.

También es útil ahondar en esta función clasificadora y en las consecuencias y lógicas inscriptas en ellas para comprender la no neutralidad de las representaciones (Raiter, 2002). Paucovich (2008:117) observa que legitimar distancias sociales hace que la producción y reproducción de "oposiciones" aparezca como "real" y "natural". Gutiérrez (2008:39) advierte, siguiendo a Bourdieu, que la estructura de dominación existe objetivamente, independientemente de los agentes y también existe en forma incorporada en esos mismos agentes. La clasificación de las diferenciaciones sociales efectuada por los agentes de la política social, contribuye a convertir y establecer estas diferencias como desigualdades, haciéndolas aparecer como "objetivas", "reales" y "naturales", como desigualdades ontológicas. Paralelamente el poder simbólico del que son portadores establece posibilidades de acción para los que son clasificados y para ellos como clasificadores, reforzando la relación de poder y su posición en la estructura socio - económica.

\subsection{Diferenciación social y demarcación de posiciones: el lugar del saber y los conocimientos.}

Aunque no fue tenido en cuenta como temática a abordar cuando nos planteamos la problemática y los interrogantes de investigación, el "conocimiento", se convirtió en un tema emergente importante durante las entrevistas, principalmente en los planificadores. En los planificadores institucional tradicionales el concepto de "conocimiento" suele estar asociado a un saber académico, mientras que en los implementadores tanto institucional tradicionales como esencialistas, es un saber hacer.Vinculado no tan directamente a un saber o a un conocimiento académico, sino a ser ellos/as portadores del saber de una cultura dominante, tanto en uno como en otro discurso se atribuyen a las distintas clasificaciones de personas pobres saberes diferentes, o directamente no saberes. En las representaciones institucionales tradicionales observamos cómo el hacedor de los programas se posiciona como actor principal y primordial, manteniendo distancia y suponiendo una desigualdad con el "beneficiario" del programa, diferencia que lo preserva de él. El foco está puesto en quienes diseñan los programas, en el proceso técnico/ 
administrativo. Al negar o no reconocer al "beneficiario" como sujeto parece haber un distanciamiento de la preocupación o el interés de los "beneficios", de los resultados, etc.. La forma en la que el planificador define su posición en la sociedad se vincula con la actitud que asume en el proceso de conocimiento. Podemos entonces analizar la relación de las acciones y las concepciones sobre la adquisición, construcción del conocimiento en los diferentes tipos de planificadores.

Para los planificadores institucionales transformadores el conocimiento se adquiere en la práctica, se construye con otros, y sirve para transformar "con" las personas que se relacionan al programa, en tanto para los institucionales tradicionales el conocimiento se adquiere en la Universidad, es diferente y superior al del pobre. Observamos que los perfiles en que el conocimiento que se valora es el científico, las acciones tienden a inmovilizar y contener "a" las personas que están vinculadas al programa, resaltamos la preposición "a" y consideramos que muestra la imposición de unos sobre otros. En el perfil en que todos quienes son parte de los programas tienen conocimiento, sean técnicos o no, este conocimiento se acrecienta y se va construyendo en el intercambio; la acción resaltada es la transformación, reforzándose la preposición “con” y designando en ella la igualdad entre los actores. Podemos observar más allá de los programas y las representaciones una diferencia que parece estar influida por la posición de implementador o de planificador. En los implementadores el conocimiento no adquiere la misma relevancia que en los planificadores, y se visualiza, como ya mencionamos, en un saber hacer o un saber vivir, y con el ser ellos portadores de una cultura y/o de una clase que sabe hacer y sabe vivir. Así en los implementadores esencialistas el no saber de las personas pobres se relaciona con el no saber leer y escribir, el no saber utilizar métodos anticonceptivos, en no saber alimentarse adecuadamente, en no saber gastar en lo que es necesario gastar, en no saber administrarse, etc. y los saberes con las estrategias de uso y "abuso" de los programas sociales.

Hablamos entonces de un capital en particular, y cómo la acumulación de este capital es producto y produce posiciones diferentes en el espacio social, observando la intervención de los agentes en esta producción. El conocimiento que se valora es paralelamente el que se adquiere en una institución legítima y legitimadora, y el que vehiculiza el habitus de determinado grupo social.

\subsection{Invisibilización - Privación de identidad: cristalización de lógicas y procesos sociales}

Tanto en las representaciones institucionales tradicionales como en las esencialistas, se resaltan las desigualdades entre no pobres y pobres; se pone énfasis por consiguiente en el componente existencial, convirtiendo las diferencias en diferencias esenciales. Se tiende a naturalizar la pobreza relacionándola con atributos de las personas pobres, dejando de lado las causas estructurales. No se toma en consideración la integralidad de las personas que viven en la pobreza y los derechos que les son violentados, sino sólo 
algunos aspectos o atributos que se les asignan y a los que se convierte en esenciales; son esos atributos los que los hacen desiguales a los no pobres. Toda construcción de representaciones proviene de seleccionar y excluir determinados elementos. En consecuencia invisibilizar es, por un lado, realizar construcciones para desligar causas y efectos y, por otro, realizar construcciones para que la persona no sea vista como tal, como poseedora de derechos, sino como responsable de su situación.

Compartimos en este sentido con Álvarez Leguizamón (2001) que las causas de la pobreza se colocan en los factores subjetivos y culturales de las personas, poniendo así el acento en las causas que la potencian y no en las causas que la producen. Esto invisibiliza las condiciones materiales que generan y agudizan la pobreza, y facilita el proceso de naturalización discursiva. Se nombra al "otro", al "pobre”, como el diferente, el desigual. Como sostiene Eroles (2005) todo lo diferente puede y debe ser invisibilizado, a los distintos o diversos se los considera inexistentes (invisibles), pues la visibilidad implica interpelación (Carballeda, 2008:51) y la interpelación cuestiona posiciones y relaciones de clases que deben permanecer inalterables.

Los agentes del la política social, por su condición de agentes del estado y por la lógica de intervención y funcionamiento de los programas, tienen el poder de legitimar posiciones de clase, comportamientos y posibilidades, de estos "otros". Si la invisibilidad de las personas pobres y de las causantes de las situaciones de pobreza se imponen, será consecuente la no necesidad de acciones para revertir la pobreza o para trabajar para la igualdad; serán legítimas las no acciones y las acciones o intervenciones que solo buscan modificar los atributos asignados a las personas pobres. Los programas sociales pueden reforzar los procesos de "exclusión", mediante acciones difusas que legitiman la desigualdad social, no parece necesario identificar e intervenir en las causas de la pobreza y en el cumplimiento de derechos (proceso de ocultamiento) sino lidiar con los pobres y la pobreza. De modos diversos en muchos de los hacedores e implementadores de programas sociales están presentes la inmovilización, la invisibilización y la privación de identidad. Puestos en juego e interrelacionados, aportan a la cristalización de lógicas y procesos sociales de construcción y refuerzo de la desigualdad social.

\section{La lógica de la igualdad y sus soportes}

No podríamos comprender la lógica de la igualdad solo por oposición a la de la desigualdad; aunque muchas de sus características se oponen a esta, también presenta elementos diferentes, que no se explican por simple contraposición. Los soportes de esta lógica muestran representaciones y mecanismos que tenderían a plantear la igualdad como principio y reconocimiento y la desigualdad existencial, la pobreza, como violación de los mismos. Recurrimos nuevamente al concepto de "privación de identidad" de Vasilachis (2003: 255), en cuanto refiere a la negación de la igualdad esencial de las personas. Si quienes definen e interpretan la pobreza pueden ser vistos como sujetos 
activos en las posibles lógicas de privación (Vasilachis, 2003: 256), también pueden ser sujetos activos y productores de esta lógica de igualdad.

\subsection{Reconocimiento de igualdad esencial y desigualdad existencial}

Los agentes que vinculamos a esta lógica, con representaciones institucionales transformadoras, parten del reconocimiento de la igualdad esencial de las personas. Esto parece no ser algo retórico sino que funciona como base para pensar las desigualdades y las acciones para influir en la transformación de esa configuración social. Son causas estructurales y políticas, y no diferencias esenciales las que determinan la desigualdad por lo tanto la pobreza no depende de características atribuibles a las personas que la viven. La desigualdad social sería entonces una producción socio política y relacional.

Ciertamente existe una pluralidad de nociones de igualdad, cuyas diferencias suelen mostrar u ocultar concepciones y políticas también distintas. En este orden de ideas Dubet (2011: 11-14) vincula la igualdad a la justicia social y afirma que en la actualidad existen dos grandes concepciones: la igualdad de posiciones o lugares y la de oportunidades. La primera busca que las distintas posiciones en la estructura social estén más próximas las unas de las otras, a costa de que entonces la movilidad social de los individuos no sea ya una prioridad. La igualdad de oportunidades, en cambio, consiste en ofrecer a todos la posibilidad de ocupar las mejores posiciones en función de un principio meritocrático. Por nuestra parte, insistimos en que es solo retórico el reconocimiento de la igualdad de todos en la postura de la igualdad de oportunidades, pues implica una diferenciación entre quienes "aprovechan" las oportunidades y quienes no lo hacen. Algunos serían meritorios y otros ineptos por no lograr hacerlo, sin mediar un reconocimiento de la desigualdad estructural que fija las desigualdades de posiciones, y cualquier posibilidad de igualdad de oportunidades. A la postura de igualdad de oportunidades estarían asociados supuestos subyacentes que mediante el recurso de postular y hacer central que algunos individuos no aprovechan las oportunidades, son ineptos; avalarían la desigualdad social, presentándola como justa.

En este soporte del reconocimiento de igualdad esencial y desigualdad existencial, no hay lugar para efectuar distinciones categoriales. Tilly (2000: 79) sostiene que el trabajo categorial siempre implica atribuir cualidades distintivas a los actores, a uno y otro lado de los límites, no apareciendo esto en la lógica de la igualdad. Los problemas organizacionales podrían entonces buscar otras vías resolutivas que las distinciones categoriales, y estas vías tendrían que ver con la apelación a la igualdad esencial, la privación de identidad que significa no reconocerla y desde ahí la violación que implica la desigualdad. Al no realizarse estas clasificaciones, también sería diferente la forma de comprenderse a sí mismos de los agentes de la política social y de definir su posición y función social. 


\subsection{Interacción y mutua transformación}

Si obviamente los agentes de la Política Social tienen otra posición que los "beneficiarios" de esa política, no interviene en esa diferencia una desigualdad esencial sino una desigualdad existencial y las lógicas que producen y refuerzan las desigualdades. Los agentes con las representaciones que vinculamos a esta lógica, reconociendo entonces la desigualdad existencial, consideran esencialmente iguales a todas las personas, con los mismos derechos, etc. y plantean la necesidad de encontrarse, de ponerse en el lugar del otro, de poner el cuerpo, interactuar y dialogar. No buscan consolidar posiciones, contener y controlar a las personas en situación de pobreza, sino trabajar conjuntamente, lograr transformaciones micro y macro sociales desde el reconocimiento de los diagnósticos, percepciones, etc. de las personas que viven la pobreza, con la intervención de las políticas públicas del estado como actor fundamental (pero no único) de una transformación que implicaría intervenir en las estructuras que generan pobreza y desigualdad.

El diálogo y la interacción son fundamentales tanto en el proceso de descubrimiento del otro como igual, como en la búsqueda de soluciones a la pobreza.Vasilachis (2003: 261) sostiene que el respeto al principio de igualdad esencial determina que las soluciones a los problemas sociales, económicos y políticos no pueden ser creadas por unos e impuestas sobre otros. Todos, como idénticamente iguales y libres, cuentan con las capacidades necesarias para participar y cooperar en la búsqueda de soluciones que no beneficien a unos sino a todos por igual.

\subsection{Visibilización y problematización de las relaciones sociales}

Desde la lógica de la igualdad se des-naturaliza la pobreza, al no esencializar los componentes existenciales y reconocer las causas estructurales. Si desde múltiples perspectivas, incluso desde las anti igualitarias, se suele reclamar igualdad en algunas esferas, si nos preguntamos igualdad en qué esferas, o igualdad de qué (de oportunidades, de posiciones, etc.) apelamos al reconocimiento de la igualdad como componente esencial de la identidad. Desde esta concepción de la igualdad se problematizan las relaciones sociales de privación, y se visibiliza la pobreza.

En esta lógica juega un papel importante la visibilización, tanto de la igualdad esencial de las personas como de las relaciones de privación y los procesos y mecanismos de esencialización de las diferencias existenciales.Visibilizar, insistimos, es reconocer la existencia, y dar lugar a la interpelación que cuestiona posiciones y relaciones de clase. 


\section{Lógicas}

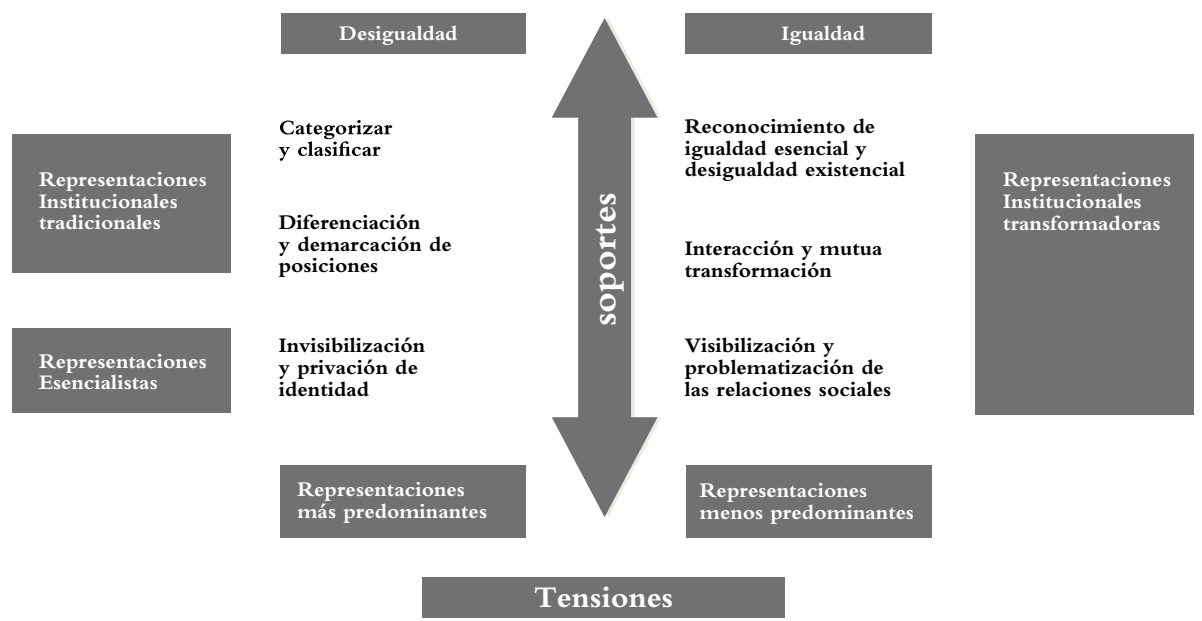

\section{Algunas conclusiones y preguntas}

A lo largo de este trabajo no solo identificamos diversos tipos de representaciones de pobres y pobreza en los agentes sino también diferentes lógicas en juego que responden a variadas perspectivas paradigmáticas y filosóficas. En las representaciones de los agentes coexisten lógicas diversas; la lógica de la desigualdad predomina pero coexiste con la lógica de la igualdad. La primera atraviesa fuertemente las representaciones que hemos llamado institucionales tradicionales y esencialistas, la segunda las representaciones institucionales transformadoras.

Gordon y Spicker (1998) sostienen que es importante identificar las representaciones sociales que contribuyen a la reproducción de la pobreza y aquellas representaciones que cuestionan el status quo y plantean alternativas de desarrollo humano que significan el cambio de dichas estructuras sociales. Sostenemos que es posible observar en los actores de la política social que hemos estudiado, un predominio las representaciones que refuerzan la desigualdad. Sin embargo esto no implica desconocer la presencia de representaciones alternativas, como las institucional transformadoras. Éstas apelan a la igualdad, reconociendo los factores objetivos de la producción y reproducción de la pobreza y planteando la necesidad de compromiso en acciones e intervenciones transformadoras. 
Afirmar que diferentes representaciones están presentes en el ámbito institucional de las políticas sociales tiene varias implicaciones. Por un lado, reafirmar la no uniformidad de las visiones y representaciones de los agentes del estado, que no son meros reproductores de los paradigmas hegemónicos en el estado; por otro, que el estado tampoco es un espacio homogéneo; representaciones contrapuestas entran en pugna por la imposición de visiones y proyectos. Vasilachis (2003: 177) plantea que cuanto menos representaciones alternativas estén presentes, cuanto menos modelos interpretativos que intenten cambiar el modelo de significados respecto de las características de una persona o de un grupo de personas estén vigentes en el mundo de la vida como esquemas comprensivos de su situación, sus relaciones, sus acciones, su identidad esencial y existencial, más enraizados estarán los procesos discriminatorios. Nos preguntamos entonces por las implicaciones de la presencia de representaciones institucionales transformadoras, como también de su gravitación diferente en comparación con las otras.

En estas múltiples representaciones las acciones en relación a las personas pobres y la pobreza son resignificadas en contenidos y modos, aunque nominalmente no se presentan con grandes diferencias. En todas ellas, hemos visto, se asigna mucha importancia a la capacitación. Así, en las representaciones que buscan la transformación se habla de encuentro, de ponerse en el lugar del otro, colaborar desde los diagnósticos de las personas pobres, problematizar, no obviar lo afectivo y político, etc. esto se enmarca en programas o elementos programáticos de capacitación. Paralelamente agentes con representaciones institucionales transformadoras, especialmente los implementadores, al hacer alusión a la intervención, vuelven a poner el acento en intervenciones más ligadas a determinadas formas de capacitación, acompañamiento y auto organización, acordes al neoliberalismo. ¿Estaremos de alguna manera ante "trampas de la acción”, que se constituyen en limitadoras para que representaciones alternativas encuentren mayores modos de expresión y visibilización? Merklen (2010:131) observa también que cuando la sociedad, políticas públicas, agencias internacionales, ONGs, ciencias sociales, y medios de comunicación, designan a ciertos grupos como pobres, los posibles repertorios de acción se encuentran un tanto predefinidos. Carballeda (2008: 68) señala como elemento recurrente en las prácticas, la vinculación casi directa de intervención en lo social con la construcción de autonomía de los sujetos "beneficiarios", entendiendo la falta de autonomía como una carencia impuesta, propia, o ligada a pautas culturales que ratifican esa condición o falta. De este modo, las dificultades de la construcción de la autonomía en un contexto de desprotección social, en donde los sujetos excluidos deben tornarse autónomos por mandatos de programas sociales o estrategias de intervención, configuran, quizás, nuevas formas de coerción ligadas a las políticas sociales focalizadas que parecen persistir. Paralelamente Edelman (1991:34) apunta que las propuestas para resolver los dilemas sociales crónicos mediante el cambio de actitudes y de conducta de los individuos son expresiones de la misma estructura de poder que crea el problema. 
Las políticas sociales implementadas a partir de 2003 han marcado un cambio respecto a los programas neoliberales. Sin embargo es posible observar aún la presencia de representaciones institucionales tradicionales y esencialistas de los pobres y la pobreza, de manera que muchas intervenciones parecen mostrar, en el plano en que este estudio se ha ubicado, los elementos aún presentes y más fijos de la política social liberal y neoliberal. Representaciones que tienen estrecha relación con la lógica de la desigualdad gravitarían más fuertemente que las representaciones vinculadas a la lógica de la igualdad. Programas y políticas, suelen estar influidas y de alguna manera heredar no solo lineamientos de las anteriores sino también actores "técnicos" con representaciones que pueden jugar un papel importante a la hora de retrasar, obstaculizar o permitir cambios, a lo que se agrega la tendencia del entramado institucional a condicionar los cambios y ser proclive a las repeticiones.

En las representaciones institucionales tradicionales y esencialistas tienen fuerza la naturalización de la pobreza y las intervenciones que, bajo diferentes nombres, responden a una lógica asistencial subyacente y arraigada y con fuerte consenso social. En consecuencia si bien en el plano del discurso los programas pueden formular ciertas modificaciones o alejamientos de la política social neoliberal, puede observarse la cristalización del asistencialismo en las representaciones y en las prácticas de gran parte de los agentes de la política social. Como ya sostuvimos, la política social estuvo más vinculada en Argentina al trabajo asalariado que a la construcción de ciudadanía; a manera de hipótesis podemos plantear que es esta una instancia que se continúa con distintas prácticas que persisten y no posibilitan esta construcción de ciudadanía. Si bien en el discurso político, y en algunos de los enunciados de los programas sociales se ve cierto distanciamiento de la visión tradicional, ésta continúa siendo predominante en las representaciones y especialmente en muchas de las prácticas de los actores. El estudio de las representaciones emerge así como una instancia compleja pero de relevante peso que puede contribuir en un mayor conocimiento de las problemáticas presentes en las políticas sociales.

\footnotetext{
${ }^{1}$ Concepto instalado por Lewis (1961), que ahondamos en puntos siguientes.

${ }^{2}$ Por "descristalización de la pobreza" hacemos referencia al proceso de sentido opuesto al que Carballeda (2008) designa con la metáfora de la "cristalización de la pobreza".

${ }^{3}$ Especialmente los documentos de la II Conferencia General del Episcopado Latinoamericano (1968), y de la III Conferencia General del Episcopado Latinoamericano (1979).

${ }^{4}$ Arias (2012) analiza la pobreza como relación social, afirmando que las formas sociales instituidas para accionar ante la pobreza definen tanto la pobreza como problema como a los pobres como sujetos.

${ }^{5}$ Grassi (2003: 223) observa que el tantas veces repetido "dar el pez, pero enseñar a pescarlo" reactualiza cada vez que se lo enuncia, el lugar donde radica la carencia, es decir en el careciente.
} 


\section{Refencias bibligráficas}

Aguilar Villanueva, Luis (1996) "Estudio introductorio". En AguilarVillanueva, Luis. La hechura de las políticas. México: Ed. Porrúa: 15-84.

Altamirano, Carlos (1990) "Lo imaginario como campo de análisis histórico y social”. En Rev.ista Punto de Vista, XIII N 38:11-14.

Álvarez Legizamón, Sonia (2001) Los cambios operados en las concepciones de gestión de programas sociales a partir del financiamiento internacional. Panel: La evaluación y gestión de las políticas sociales en las últimas dos décadas: problemas y perspectivas. Documento presentado en elVI Congreso Internacional del CLAD sobre la Reforma del Estado y de la Administración Pública. Buenos Aires.

(1998) "Solidaridad privada e indiferencia pública, la nueva cara de la Política Social para los excluidos". En Revista Umbrales Nº: 9-31.

Arias, Ana Josefina (2012) Pobreza y modelos de intervención. Aportes para la superación del modelo de asistencia. Buenos Aires: Ed. Espacio.

Auyero, Javier (2001) La Política para pobres. Buenos Aires: Manantial.

Baczko, Branislaw (1991) Los imaginarios sociales. Memorias y esperanzas colectivas. Buenos Aires: Nueva Visión.

Bourdieu, Pierre (1985) ¿Qué significa hablar? Economía de los intercambios lingüísticos. Madrid: Akal/universitaria.

(1996) Espíritus de Estado. Génesis y estructura del campo burocrático. Revista de Ciencias Sociales, 8: 5 -29.

Carballeda, Alfredo (2008) Los cuerpos fragmentados. La intervención en lo social en los escenarios de la exclusión y el desencanto. Buenos Aires: Paidós.

Cardarelli, Graciela y Rosenfeld, Mónica (2000) Con las mejores intenciones. Acerca de la relación entre el Estado pedagógico y los agentes sociales. En Duschatzky, Silvia. (comp.). Tutelados y asistidos. Buenos Aires: Paidos: 23-67.

Conferencia General del Episcopado Latinoamericano (II) (1968) Documento de Medellín. Buenos Aires: Ed. San Pablo. 
Conferencia General del Episcopado Latinoamericano (III) (1979) Documento de Puebla. Buenos Aires: Ed. San Pablo.

Danani, Claudia (1996) "Algunas posiciones sobre la Política Social como campo de estudio y la noción de población objetivo”. En Hintze, Susana (org.), Política Social. Contribución al debate teórico - metodológico. Buenos Aires: CEA-UBA:21-38.

Danani, Claudua y Hintze, Susana (2012) Protecciones y desprotecciones: la seguridad social en la Argentina 1990-2010. Buenos Aires: Universidad Nacional de General Sarmiento.

Dubet, François (2011) Repensar la justicia social. Buenos Aires: Siglo XXI Editores.

Edelman, Murray (1991) La construcción del espectáculo político. Buenos Aires: Manantial.

Eroles, Carlos (2005) "La discapacidad como eje de un movimiento social de afirmación de derechos". En Eroles, Carlos. y Ferreres, Carlos. (Coords.) La discapacidad: una cuestión de derechos humanos. Buenos Aires: Ed. Espacio: 15 - 39.

Escolar, Cora (2000) “La recuperación del análisis institucional como perspectiva teórico metodológica". En Escolar, Cora (comp.). Topografías de la Investigación. Buenos Aires: Eudeba: 29-47.

Foucault, Michel (1993) Microfísica del poder. Madrid: La Piqueta.

Gordon, David y Spicker, Paul (1998) The International Glossary on Poverty. London: ZED-CROP.

Grassi, E. (2003) Políticas y Problemas Sociales en la Sociedad Neoliberal. Buenos Aires: Ed. Espacio.

Gutiérrez, Alicia (2008) “El «capital social» en la pobreza: apuesta, medio y resultado de luchas simbólicas”. En Pavcovich, Paula y Truccone, Damian (comp.) Estudios sobre pobreza en Argentina. Villa María: Eduvim: 29-48.

Lautier, Bruno (1998) "Pauvreté et politiques de la pauvreté au Mexique". En Poulin, Richard y Salama, Pierre (comp..) L' insoutenable misère du monde. Economie et sociologie de la pauvreté. Québec:Vents d'Ouest, Hull: 159 -211.

Lewis, Oscar (1961) Los Hijos de Sánchez. México: Fondo de Cultura Económica. 
Martínez, Ana Teresa (2007) Pierre Bourdieu. Razones y lecciones de una práctica sociológica. Buenos Aires: Manantial.

Mercklen, Denis (2010) Pobres ciudadanos. Las clases populares en la era democrática (Argentina 1983-2003). Buenos Aires: Gorla.

Moscovici, Serge (1981) “On social representation”. En Forgas, J.P. (Comp.) Social cognition. Perspectives in everyday life. Londres: Academic Press: 303-317.

(1986) Psicología Social II. Pensamiento y vida social. Psicología Social y problemas sociales. Barcelona: Paidós.

Murillo, Susana (2008) "Producción de pobreza y construcción de la subjetividad". En Cimadamore, Alberto y Cattani, Antonio (Coord.), Producción de pobreza y desigualdad en América Latina. Bogota: CLACSO - CROP: 41-78

Pavcovich, Paula (2008) "Clases, posiciones, puntos de vista". En Pavcovich, Paula y Truccone, Damián (comp.) Estudios sobre pobreza en Argentina. Villa María: Eduvim: 101-134.

Raiter, Alejandro (2002) "Representaciones sociales”. En Raiter, Alejandro y Zullo, Julia (comp.) Representaciones Sociales. Buenos Aires: Eudeba: 11-29.

Ruiz Olabuenaga, José (1996) Metodología de la investigación cualitativa. Bilbao: Universidad de Deusto.

Svampa, Maristella (2001) Los que ganaron. La vida en los countries y en los barrios privados. Buenos Aires: Ed. Biblos.

Taylor, Steven y Bogdan, R. (1986) Introducción a los métodos cualitativos. Buenos Aires: Paidos.

Tenti Fanfani, Emilio (1992) “Representación, delegación y acción colectiva en comunidades urbanas pobres”. En Lumi, Susana; Golbert, Laura y Tenti Fanfani, Emilio (coord.) La mano izquierda del Estado. La asistencia social según los beneficiarios. Buenos. Aires: Miño y Dávila editores: 125-160.

Tilly, Charles (2000) La desigualdad persistente. Buenos Aires: Manantial.

Vasilachis, Irene (2003). Pobres, pobreza, identidad y representaciones sociales. Barcelona: Gedisa. 